\title{
Author Correction: A comparison of tools for the simulation of genomic next-generation sequencing data
}

\section{Merly Escalona, Sara Rocha and David Posada}

Nature Reviews Genetics (2016) https://doi.org/10.1038/nrg.2016.57 Published online 20 June 2016

The originally published article contained errors in FIG. 1 (Decision tree for the selection of a suitable NGS genomic simulator), whereby the labels 'Variants' and 'No Variants' had been switched. The correct figure is presented in this notice.

https://doi.org/10.1038/s41576-018-0058-2 I Published online 3 October 2018

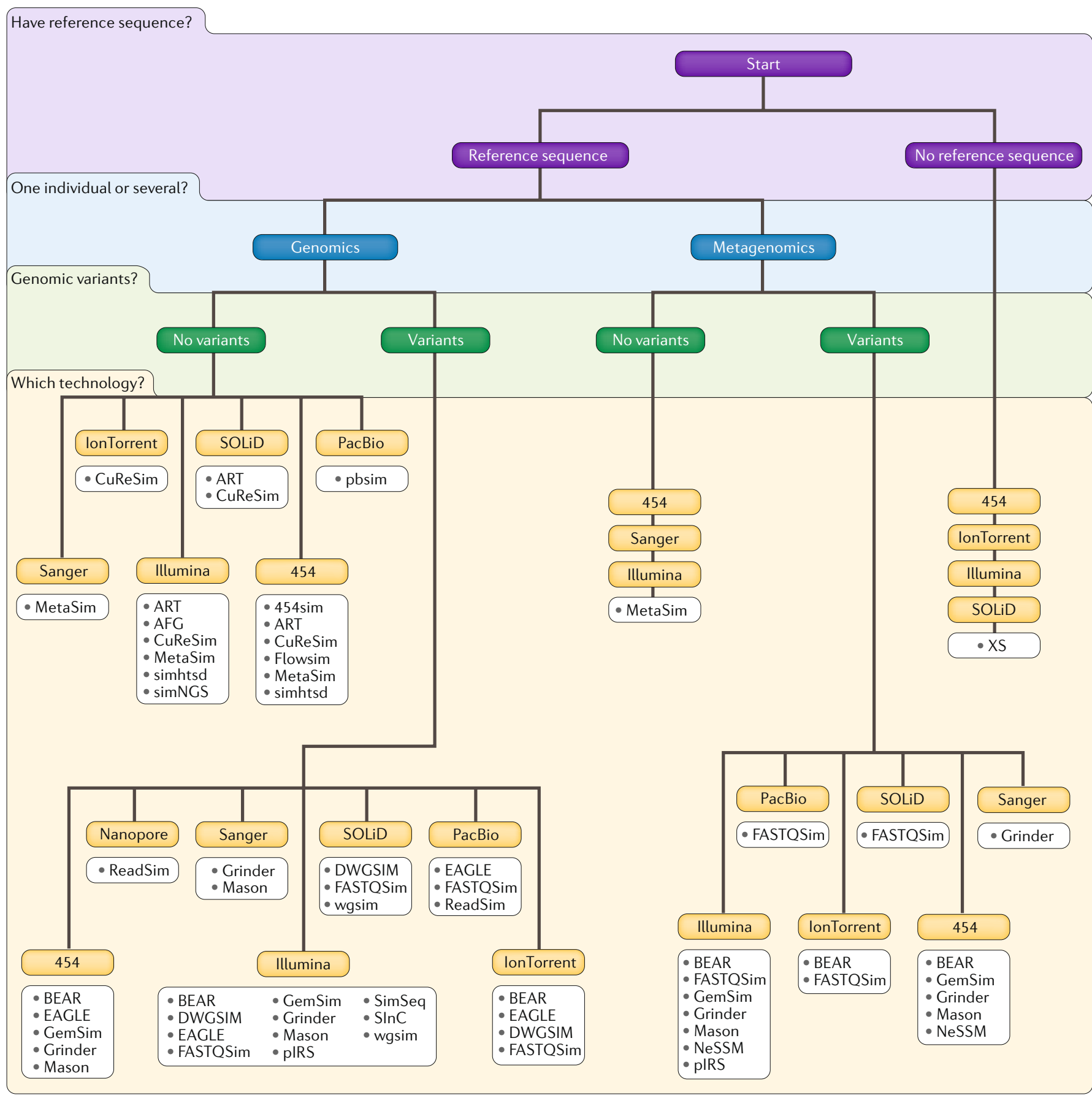

Fig. 1 